\title{
Raptors, racing pigeons and perceptions of attacks
}

\author{
Esther F. Kettel ${ }^{1} \cdot$ Richard W. Yarnell $^{1} \cdot$ John L. Quinn ${ }^{2} \cdot$ Louise K. Gentle $^{1}$
}

Received: 27 July 2020 / Revised: 22 March 2021 / Accepted: 9 July 2021 / Published online: 20 July 2021

(c) The Author(s) 2021

\begin{abstract}
Raptors are often the cause of human-wildlife conflict because they may predate economically valuable species, and it is the perceived extent of predation that may augment conflict between raptors and people who keep and race pigeons. This study uses data obtained through questionnaires and an online raptor-attack reporting feature to investigate the frequency of racing pigeon losses and the perceptions of pigeon fanciers. Responses suggest that those who kept more pigeons and entered more races lost a higher proportion of pigeons. Losses were also influenced by the predatory species: sparrowhawks (Accipter nisus) were more likely to attack pigeons at lofts, whilst peregrines (Falco peregrinus) were more likely to attack pigeons during training, with patterns linked to the raptors' breeding seasons. Pigeon fanciers were almost unanimous in their perception that raptors threaten the future of the hobby. Previous studies show that only a small proportion of racing pigeons are likely to be lost to raptors, yet pigeon fanciers believe that raptors are the main cause of losses, highlighting a possible mismatch between the perceived and actual causes of loss. This misconception may be a main source of this human-raptor conflict, so educating pigeon fanciers about the true impact of raptors could help to alleviate the issue. A shift in the beginning of the pigeon racing season by one month, and careful sighting of pigeon lofts in gardens, are also recommended in order to reduce raptor attacks.
\end{abstract}

Keywords Peregrine falcon $\cdot$ Sparrowhawk $\cdot$ Columba livia $\cdot$ Pigeon fancier $\cdot$ Human-wildlife conflict

\section{Background}

Many species of raptor currently face, or have faced in the past, population declines as a result of persecution (e.g. Etheridge et al. 1997; Smart et al. 2010; Amar et al. 2012), the main cause of raptor population limitation globally (Newton 1998). Persecution of raptors occurs due to the real or perceived limiting effect that they have on prey species that hold socio-economic value, such as livestock or game species (Woodroffe et al. 2005).

Many raptor populations in the United Kingdom (UK) have recovered after suffering severe declines during the early 1960s due to the use of organochlorine pesticides (Newton 2017). Following these population recoveries, peregrine falcons (Falco peregrinus) and Eurasian sparrowhawks (Accipiter nisus) have colonised human-dominated

Esther F. Kettel

esther.kette102@ntu.ac.uk

1 School of Animal, Rural and Environmental Sciences, Nottingham Trent University, Brackenhurst Campus, Nottinghamshire NG25 0QF, UK

2 School of Biological, Earth and Environmental Sciences, University College Cork, North Mall, Cork, Ireland environments (Ratcliffe 2010), which may augment humanraptor conflict as raptors come into closer and more frequent contact with humans and species that hold value, including domesticated species (Henderson et al. 2004; Amar et al. 2012).

Of those convicted of raptor-related persecution in the UK between 1990 and $2019(n=181), 67 \%$ were gamekeepers (RSPB 2020). Indeed, raptor persecution on land managed for driven red grouse (Lagopus lagopus scotica) shooting, in particular, has received much attention (e.g. Thirgood et al. 2000; Thirgood and Redpath 2008; Thompson et al. 2016). Although to a lesser extent, pigeon fanciers - those who keep and race domesticated pigeons (Columba livia domestica) — have also been convicted of raptor-related persecution offences in the UK (5.5\% of 181 convictions; RSPB 2020). As such, conflict between raptors and pigeon fanciers has received less attention in the literature.

Pigeon racing is a popular hobby during which domesticated pigeons are 'liberated' from a location before racing to their home loft. The 13 million racing pigeons in the UK (RSPB 2008), owned by at least 60,000 pigeon racers (Royal Pigeon Racing Association 2021), can act as a food supply for predators during the racing season (April-September). Racing pigeons tend to fly over open ground, so are vulnerable to attacks from raptors 
such as peregrines and sparrowhawks (Henderson et al. 2004), and few species are as profitable as racing pigeons in terms of ease of capture and weight. One study found that some peregrines are thought to have a predominance of domestic pigeons in their diet during the breeding season, particularly when close to racing routes (Dixon et al. 2003), but others have shown that only a small proportion of pigeon losses are attributed to peregrines (Shawyer et al. 2003; Parrott et al. 2008). The proportion of racing pigeons in the diet of sparrowhawks has not been extensively researched, although one study suggests that domesticated pigeons constituted only $0-0.19 \%$ of kills (Newton and Marquiss 1982). Around 50\% of racing pigeons fail to return to their home loft each year (Shawyer et al. 2003) and, whether related or not, losses of pigeons are believed to have increased alongside the growing raptor populations (Henderson et al. 2004).

Raptor predation of racing pigeons is a contentious issue (Shawyer et al. 2003; Henderson et al. 2004; Parrott et al. 2008) and cases of illegal persecution by pigeon fanciers exist, whereby raptors are poisoned or their nests destroyed (RSPB 2014). Research quantifying the extent of raptor predation on racing pigeons is important. However, it is also the perceived extent of predation that causes conflict: if pigeon fanciers believe predators are threatening the hobby, conflict arises regardless of their actual impact. People's perceptions and actual losses of prey species may differ, as has been seen in other raptor-related conflicts (e.g., Ballejo et al. 2020), and understanding differences between stakeholder perceptions and actual losses may help to resolve conflicts through, for example, environmental education (Cailly Arnulphi et al. 2017; Duriez et al. 2019). Nevertheless, perceptions of stakeholders are rarely used to inform evidence-based conservation actions and conflict resolutions (Bennet 2016).

Here, we use data obtained from questionnaires and an online raptor-attack reporting feature to report: (1) the frequency of racing pigeon losses in relation to number of races entered and number of pigeons owned, (2) the location of raptor attacks (specifically attacks from peregrine and sparrowhawk), (3) the timing of peregrine and sparrowhawk attacks in relation to raptor breeding seasons and the pigeon racing calendar, and (4) the attitudes of pigeon fanciers towards peregrines and sparrowhawks. Understanding human attitudes and patterns in predation is pertinent for mitigation, management and resolution of this humanwildlife conflict.

\section{Methods}

\section{Questionnaires}

Questionnaires aimed at pigeon fanciers were conducted to obtain information on the numbers of racing pigeons owned, races entered, pigeons lost per year, observed raptor attacks, locations of raptor attacks, and the main reasons for losses (Supplementary Material). Questions regarding opinions towards raptors were also asked. Questionnaires were available online (Bristol Online Surveys 2016) from 15 February 2016 to 09 May 2016, at which point responses declined considerably. Questionnaires were also printed in 'Racing Pigeon Magazine' and 'British Homing World' : two leading pigeon racing publications in the UK.

\section{Hawkwatch}

The Royal Pigeon Racing Association (RPRA) runs 'Hawkwatch' (http://www.rpra.org/raptor-alliance/), which allows members of the public to report raptor attacks on racing pigeons. Reports include geographical location, date and raptor species. As most attacks involved peregrines or sparrowhawks, analyses were restricted to these species. Hawkwatch data were obtained from attacks witnessed between 13 March 2012 (when reporting began) and 9 May 2016 (the end of the questionnaire). These were used to calculate (1) the percentage of attacks by peregrines and sparrowhawks and (2) the percentage of attacks during different months of the year.

\section{Statistical analyses}

Ordinal regression models were undertaken to test the effects of (1) the number of races entered per year and (2) the number of racing pigeons owned, on the number of racing pigeons lost per year $(1-5,6-10,11-20,>20 ; 0$ category was omitted due to a low sample size), where 'number of pigeons lost' was fitted as the reponse variable and 'number of races entered per year' and 'number of racing pigeons owned' were fitted as explanatory variables. Statistical analyses were conducted in Minitab (version 18.1).

\section{Results}

\section{Frequency of racing pigeon losses}

A total of 665 people responded to the questionnaire. The return rate varied regionally, with the highest response rate from England (63.91\%), followed by Scotland (20.60\%), Wales (7.22\%), the Republic of Ireland (3.01\%) and Northern Ireland (2.56\%). The remaining respondents were from countries other than those in the UK and Ireland (1.65\%) or chose not to answer (1.05\%).

A mean of $78.25( \pm 1 \mathrm{SE} 1.75)$ pigeons were kept per loft, and $18.66( \pm 1$ SE 0.33$)$ races were entered per year. Just under half of the respondents lost over 20 pigeons per year (the highest pigeon loss category; Table 1), irrespective of cause. There were significant correlations between both the number of races entered and the number of pigeons owned, on the 
Table 1 Number of racing pigeons lost (reasons undetermined) per year in relation to the number owned and races entered

\begin{tabular}{|c|c|c|c|c|}
\hline $\begin{array}{l}\text { Number of } \\
\text { pigeons lost per } \\
\text { year }\end{array}$ & $\begin{array}{l}\text { Percentage of people to lose } \\
\text { pigeons in each loss category }(\%)\end{array}$ & $\begin{array}{l}\text { Mean number of races } \\
\text { entered }( \pm 1 \mathrm{SE})\end{array}$ & $\begin{array}{l}\text { Mean number of } \\
\text { pigeons owned }( \pm 1 \\
S E)\end{array}$ & $\begin{array}{l}\text { Percentage of pigeons lost in relation } \\
\text { to mean number of pigeons owned }(\%)\end{array}$ \\
\hline None & 0.53 & $6.67( \pm 6.67)$ & $24.67( \pm 8.67)$ & 0 \\
\hline $1-5$ & 5.81 & $15.86( \pm 1.49)$ & $50.88( \pm 6.73)$ & $1.97-9.83$ \\
\hline $6-10$ & 18.49 & $20.657( \pm 0.67)$ & $65.05( \pm 3.62)$ & $9.22-15.37$ \\
\hline $11-20$ & 30.11 & $21.09( \pm 0.62)$ & $69.66( \pm 2.26)$ & $15.79-28.71$ \\
\hline$>20$ & 44.89 & $23.52( \pm 0.71)$ & $87.98( \pm 2.44)$ & $23.87+$ \\
\hline
\end{tabular}

number of pigeons lost per year $\left(Z_{(567)}=-8.17, p<0.001\right.$; $Z_{(566)}=-7.70, p<0.001$, respectively), where more races entered and more pigeons owned were associated with a higher number of losses. In addition, the percentage of pigeons lost in relation to the mean number of pigeons owned was greater with more pigeons owned (Table 1). However, greater losses at larger lofts may not be due to raptors alone, as those who believed disease as the main cause of loss kept an average of 118 birds, 40 more than lofts where raptors were cited as the main cause of loss.

\section{Location of raptor attacks}

The majority of respondents $(98 \%)$ correctly identified a peregrine and $76 \%$ correctly identified a sparrowhawk in a picture shown.

Respondents were asked if they had ever witnessed an attack by a peregrine or sparrowhawk in different situations; $72 \%$ and $98 \%$ of respondents observed an attack at the loft by peregrines or sparrowhawks, respectively.
Sixty percent of attacks witnessed and reported on Hawkwatch $(n=1049)$ took place at lofts; of these attacks $35 \%$ were by peregrines and $65 \%$ by sparrowhawks.

Findings from the questionnaire indicated that attacks were also observed during training ( $74 \%$ observed peregines; $37 \%$ observed sparrowhawks) or during a race ( $30 \%$ observed peregines; $13 \%$ observed sparrowhawks).

\section{Timing of raptor attacks}

Hawkwatch data revealed that the percentage of peregrine attacks $(n=222)$ increased from January to April, peaking in June. Attacks then decreased rapidly and were minimal between September and December (Fig. 1). The percentage of sparrowhawk attacks $(n=405)$ was minimal from May to December, and throughout most of the racing season (April-September). Attacks increased in January, peaking in March and April, before declining in May (Fig. 1).
Fig. 1 Percentage of attacks on racing pigeons witnessed at lofts by peregrines $(n=222)$ and sparrowhawks $(n=405)$ from March 2012 to May 2016. Grey shading represents the pigeon racing season

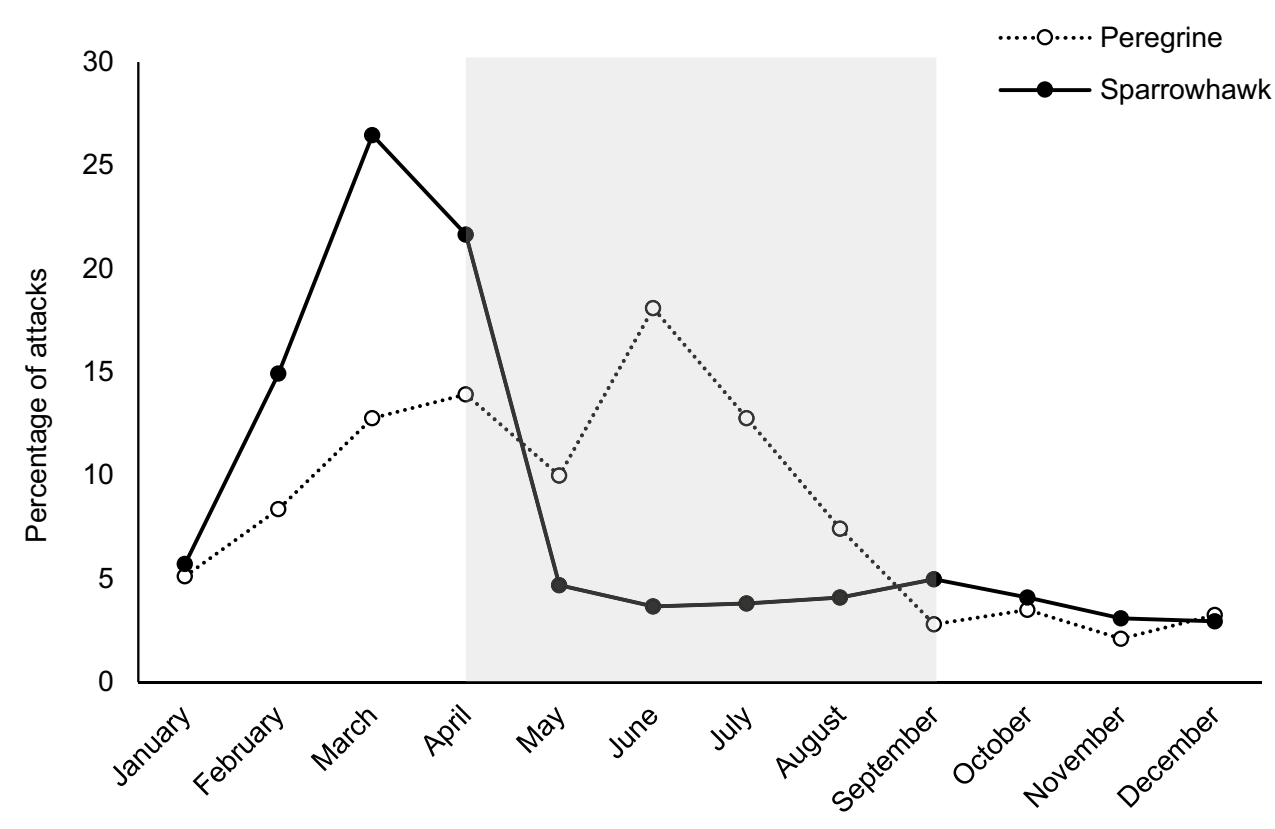




\section{Attitudes towards raptors}

Almost all respondents believed that raptors threaten the future of pigeon racing (98\%), and that there should be measures to control peregrines (98\%) and sparrowhawks (98\%). The majority of respondents (84\%) believed raptor attacks were the main cause of pigeon losses. Few respondents thought mis-navigation (5\%), collisions with humanmade objects $(2 \%)$, terrestrial predators $(2 \%)$ or disease $(0.5 \%)$ were the main causes of loss.

\section{Discussion}

The questionnaire response rate represented around one percent of the $\sim 60,000$ pigeon fanciers in the UK. Thus, although the questionnaire does not represent all pigeon fanciers, it gives a representation of how this stakeholder group perceives raptor attacks in the UK. The respondents were almost unanimous in the belief that raptor attacks threaten the future of the hobby and that there should be political measures to control numbers. However, before conclusions are drawn, it should be noted that the data presented here are inherently biased because, for example, those who did not respond to the questionnaire may not have witnessed attacks and those who did respond may have had an interest in the work because they had already witnessed raptor attacks on their pigeons. Nevertheless, the results from this study may go some way into resolving conflicts.

\section{Frequency of racing pigeon losses}

Around half of the respondents reported losses in the highest category ( $>20$ pigeons per year), irrespective of cause. Those who kept more pigeons and entered more races lost a higher percentage of pigeons (Table 1). Although it might be expected that larger flocks are safer due to the dilution effect and shared vigilance, this finding suggests that larger lofts and more frequent activity are more obvious to predators, thus more likely to be targeted and subject to repeat attacks (Cresswell and Quinn 2011). Furthermore, straying, exhaustion, collisions and shooting/poisoning have been shown to be causes of losses during races (Shawyer et al. 2003), so will escalate with increasing races entered.

Evidence here suggests that keeping a maximum of 50 pigeons ( 28 fewer than average), and entering 13 races annually (seven fewer races than average), would result in the lowest losses ( $0-5$ pigeons) to all causes. As such, these numbers are recommend in order to reduce pigeon losses. However, these findings and recommendations are based on the assumption that all pigeons are of equal quality (e.g. homing ability) and that all pigeons have an equal probablility of being targeted, irrespective of quality. In reality, these assumptions are unlikely to be true because individuals always vary in quality, and evidence from other systems suggest that raptors target individuals in flocks in a non-random manner (Cresswell and Quinn 2011). Therefore, if these assumptions are false, an alternative recommendation of increasing flock size to dilute the risk of high quality individuals being predated may be preferable.

\section{Location and timing of raptor attacks}

Peregrines of both sexes are large enough to hunt pigeons (Ratcliffe 2010). However, only female sparrowhawks are large enough to hunt pigeons and, during the breeding season, only the male hunts (Newton 1986). The breeding seasons also differ in the UK; peregrines begin egg-laying in March/April, whilst sparrowhawks start in May. This is reflected in the timing of attacks. Sparrowhawk attacks peak in February/March (Fig. 1); thus, sparrowhawks are only attacking pigeons in large numbers before the hawk's breeding season, coinciding with the period when training and exercise of pigeons increases. It is unlikely that sparrowhawks depend on racing pigeons as a food source and are instead taking advantage of an increase in food. Delaying the pigeon racing season by one month, and limiting training until after May, may therefore drastically reduce the number of attacks on racing pigeons by sparrowhawks. However, peregrine attacks peak in June during the middle of the racing season (Fig. 1), and so a one month shift of the racing season may not be enough where peregrine attacks are common. The peak in peregrine attack occurs when peregrine chicks are also likely to be fledging. This coincides with previous work (Dixon et al. 2003) and indicates that peregrines are also taking advantage of an increase in prey during the breeding season, particularly once young have fledged.

Differences in raptor ecology were also apparent from the locations of the reported attacks: sparrowhawks attacked primarily at the loft, whereas peregrines attacked during training and races. Similar findings have been reported previously (Shawyer et al. 2003; Henderson et al. 2004), although the number of peregrine attacks at the loft during this study was much higher. This warrants further study to see whether this is a misconception, or whether peregrines are learning to exploit prey at the loft, posing more of a problem than has been reported previously. The higher frequency of sparrowhawk attacks at the loft is unsurprising as they prefer to attack from cover (Creswell and Quinn 2010), highlighting that the removal of ambush sites such as bushes around lofts could limit pigeon loss.

In summary, raptor attacks could be reduced by: (1) exercising pigeons after May, when female sparrowhawks are likely to be on the nest; (2) altering the racing season so that it does not coincide with the raptor breeding seasons; and (3) locating lofts away from trees or cover, from which sparrowhawks launch their attacks. 


\section{Attitudes towards raptors}

Raptor attacks were perceived as the main cause of pigeon losses (84\%), with few losses to other causes. Although we could not directly compare these perceived losses with actual losses, these findings contrast with studies that have investigated racing pigeon deaths by investigating the diet of the raptors (Parrott et al. 2008) or pigeons taken to wildlife hospitals (Shawyer et al. 2003), where only a small proportion of losses were attributed to raptors. Whilst is is difficult to assess the true extent of pigeon losses to different causes, these differences highlight a potential mismatch between the perceived and actual causes of loss. For example, whilst peregrines and sparrowhawks are likely to predate on racing pigeons-particularly at certain times of the year and given the high number of pigeons available during the racing season ( 13 million (RSPB 2008)) other factors are also likely to play a part in losses (e.g. disease, straying etc.). More research needs to be done to establish whether there is a true mismatch between perceptions and reality.

Respondents expressed anger that raptors have increased in recent decades and that this is actively encouraged by conservation organisations, for example, by installing nest boxes to attract raptors to particular locations or through reintroducing individuals. However, nest boxes are not typically used by sparrowhawks, and peregrine boxes are usually only installed after a pair has prospected a suitable nesting site. Moreover, neither species has been part of reintroduction efforts in the UK. Thus, there may be some misunderstanding by pigeon fanciers in terms of the conservation approaches that have been adopted for these two raptor species. Opening a dialogue between fanciers and local conservation organisations would be a useful step in resolving this conflict and has been suggested to help resolve conflicts between other raptors species and stakeholders (e.g. Cailly Arnulphi et al. 2017; Duriez et al. 2019).

Generally, pigeon fanciers have an aging profile (Shawyer et al. 2003). As such, many will have started pigeon racing when raptor numbers were at their lowest. Declines in the UK in the 1960s were largely attributed with the use of organochlorine pesticides, but populations of raptors have recovered following a ban on these pesticides alongside legal protection of wildlife (Newton 2017). As indicated by the questionnaire responses, some pigeon fanciers believe that the future of pigeon racing is threatened by a perceived 'explosion' in the numbers of raptors. The population recovery of sparrowhawks and peregrines may, in part, explain these negative perceptions. Indeed, human-wildlife conflicts are particularly intense where predatory species are recovering in places where they were once absent (Woodroffe et al. 2005).
Almost all respondents believed that there should be measures to control peregrines and sparrowhawks, illustrating the real concern of fanciers. However, the likelihood of this is doubtful due to the severity of previous raptor declines and the degree of protection offered to them. Furthermore, as territories are re-occupied when they become available, a huge number of raptors would have to be killed, which would be neither sustainable nor palatable to most of society.

In conclusion, it is not in the interest of those wishing to protect raptors, nor pigeon fanciers, for the hobby to cease, but rather, to reach a resolution to prevent the illegal disturbance and killing of raptors whilst allowing pigeon fancying to continue. For this to happen, a change in practice (e.g. through shifting the timing of the racing season) and educating fanciers on how and why raptor species may have increased in recent decades, may be options to reduce attacks and alleviate this human-wildlife conflict.

Supplementary information The online version contains supplementary material available at https://doi.org/10.1007/s10344-021-01513-2.

Acknowledgements We thank everyone that completed the questionnaire and Stewart Wardrop from the Royal Pigeon Racing Association who supported distribution of the questionnaire and provided Hawkwatch data.

Author contribution All authors contributed to the study conception and design. Material preparation, data collection, and analysis were performed by EK with additonal analysis by LG and JQ. The first draft of the manuscript was written by EK, and all authors commented on previous versions of the manuscript. All authors read and approved the final manuscript.

Funding This work was funded by a Nottingham Trent University Vice Chancellor's Scholarship awarded to EK.

Availability of data and material Data may be made available by contacting the corresponding author.

\section{Declarations}

Ethics approval Procedures accorded with Nottingham Trent University's ethics committee.

Conflict of interest The authors declare no competing interests.

Open Access This article is licensed under a Creative Commons Attribution 4.0 International License, which permits use, sharing, adaptation, distribution and reproduction in any medium or format, as long as you give appropriate credit to the original author(s) and the source, provide a link to the Creative Commons licence, and indicate if changes were made. The images or other third party material in this article are included in the article's Creative Commons licence, unless indicated otherwise in a credit line to the material. If material is not included in the article's Creative Commons licence and your intended use is not permitted by statutory regulation or exceeds the permitted use, you will need to obtain permission directly from the copyright holder. To view a copy of this licence, visit http://creativecommons.org/licenses/by/4.0/. 


\section{References}

Amar A, Court IR, Davison M, Downing S, Grimshaw T, Pickford T, Raw D (2012) Linking nest histories, remotely sensed land use data and wildlife crime records to explore the impact of grouse moor management on peregrine falcon populations. Biol Conserv 145:86-94

Ballejo F, Plaza PI, Lambertucci SA (2020) The conflict between scavenging birds and farmers: Field observations do not support people's perceptions. Biol Conserv 248:108627

Bennet NJ (2016) Using perceptions as evidence to improve conservation and environmental management. Conserv Bio 30:582-592

Bristol Online Surveys (2016) BOS: powerful, flexible online surveys [online]. Available at: https://www.onlinesurveys.ac.uk/ (Accessed 09 June 2016)

Cailly Arnulphi VB, Lambertucci SA, Borghi CE (2017) Education can improve the negative perception of a threatened long-lived scavenging bird, the Andean condor. PloS One 12:e0185278

Cresswell W, Quinn JL (2010) Attack frequency, attack success and choice of prey group size for two predators with contrasting hunting strategies. Anim Behav 80:643-648

Cresswell W, Quinn JL (2011) Predicting the optimal prey group size from predator hunting behaviour. J Anim Ecol 80:310-319

Dixon A, Richards C, Lawrence A, Thomas M (2003) Peregrine (Falco peregrinus) predation on racing pigeons (Columba livia) in Wales. In: Thompson DBA, Redpath SM, Fielding AH, Marquiss M, Galbrraith CA (eds) Birds of prey in a changing environment. The Stationary Office Ltd., Edinburgh, pp 255-261

Duriez O, Descaves S, Gallais R, Neouze R, Fluhr J, Decante F (2019) Vultures attacking livestock: a problem of vulture behavioural change or farmers' perception? Bird Conserv Int 29:437-453

Etheridge B, Summers RW, Green RE (1997) The effects of illegal killing and destruction of nests by humans on the population dynamics of the hen harrier Circus cyaneus in Scotland. J Appl Eco 34:1081-1105

Henderson I, Parrott D, Moore N (2004) Racing pigeons - impact of raptor predation. A report to Sottish Natural Heritage and Scottish Homing Union. Central Science Laboratory, North Yorkshire

Newton I (1986) The sparrowhawk. T \& A D Poyser Ltd., Hertfordshire

Newton I (1998) Population limitation in birds. Academic Press, London

Newton I (2017) Invited commentary: fifty years of raptor research. J Raptor Res 51:95-106
Newton I, Marquiss M (1982) Food, predation and breeding season in sparrowhawks (Accipiter nisus). J Zool 197:221-240

Parrott D, Henderson I, Deppe C, Whitfield P (2008) Scottish racing pigeons killed by peregrine falcons Falco peregrinus: estimation of numbers from ring recoveries and peregrine daily food intake. Bird Study 55:32-42

Ratcliffe DA (2010) The peregrine falcon, 2nd edn. T \& AD Poyser Ltd., London

Royal Pigeon Racing Association (2021) About RPRA [online]. Available at: https://www.rpra.org/about-rpra/ (Accessed 05 March 2021)

RSPB (2008) Racing pigeons and birds of prey. A report by the RSPB, Bedfordshire

RSPB (2014) The illegal killings of birds of prey on Scotland 1994 2014: a review. A report by the RSPB, Bedfordshire

RSPB (2020) Birdcrime 2019: exposing bird of prey persecustion in the UK. A report by the RSPB, Bedfordshire

Shawyer CR, Clarke R, Dixon N (2003) Causes of racing pigeon (Columba livia) losses, including predation by raptors, in the United Kingdom. In: Thompson DBA, Redpath SM, Fielding AH, Marquiss M, Galbrraith CA (eds) Birds of prey in a changing environment. The Stationary Office Ltd., Edinburgh, pp 263-268

Smart J, Amar A, Sim IMW, Etheridge B, Cameron D, Christie G, Wilson JD (2010) Illegal killing slows population recovery of a re-introduced raptor of high conservation concern - the red kite Milvus milvus. Biol Conserv 143:1278-1286

Thirgood S, Redpath S (2008) Hen harriers and red grouse: science, politics and human- wildlife conflict. J App Eco 45:1550-1554

Thirgood S, Redpath S, Newton I, Hudson P (2000) Raptors and red grouse: conservation conflicts and management solutions. Conserv Bio 14:95-104

Thompson PS, Douglas DJT, Hoccom DG, Knott J, Roos S, Wilson JD (2016) Environmental impacts of high-output driven shooting of red grouse Lapogus lapogus scotia. Ibis 158:446-452

Woodroffe R, Thirgood S, Rabinowitz A (2005) The impact of humanwildlife conflict on natural systems. In: Woodroffe R, Thirgood S, Rabinowitz A (eds) People and wildlife: conflict or coexistence? Cambridge University Press, Cambridge, pp 1-12

Publisher's Note Springer Nature remains neutral with regard to jurisdictional claims in published maps and institutional affiliations. 